\title{
Research on Logistics Cost Control of E-commerce Enterprise from the Perspective of Value Chain-A Case Study of Pinduoduo
}

\author{
Guo Guihang ${ }^{1}$, Wu Yanqin ${ }^{1} \&$ Guo Chuyao ${ }^{2}$ \\ ${ }^{1}$ School of English for International Business, Guangdong University of Foreign Studies, Guangzhou, China \\ ${ }^{2}$ School of Economics \& Management, South China Normal University, Guangzhou, China \\ Correspondence: Guo Guihang, School of English for International Business, Guangdong University of Foreign \\ Studies, No.2 Baiyundadaobei, Guangzhou 510420, China. Tel: 86-20-3620-7158. E-mail: \\ guihang@gdufs.edu.cn
}

Received: May 10, 2021

Accepted: May 29, 2021

Online Published: June 5, 2021

doi:10.5539/ijef.v13n7p42

URL: https://doi.org/10.5539/ijef.v13n7p42

\begin{abstract}
Recently, with the rapid development of social platforms, social e-commerce enterprises are also rising. However, in the process of development, logistics cost has become a big constraint. Taking Pinduoduo as an example, this paper adopts case analysis method and literature review method to study how to help e-commerce enterprises control logistics costs from the perspective of value chain. By analyzing, this paper finds that for internal value chain of Pinduoduo, it faces problems of inadequate supervision of delivery cost, unreasonable freight rate, and high reverse logistic cost. For external value chain, Pinduoduo faces problems of low loyalty from users, high competitiveness from competitors and imperfect sinking market value chain. Aiming at these problems, this paper puts forward the following suggestions. For internal value chain, Pinduoduo should adopt JIT and ABC method, strengthen the supervision of delivery cost, and improve the efficiency of after-sale service. For external value chain, Pinduoduo needs to establish strong relationship with suppliers and customers. Most importantly, forming an infallible information system is essential.
\end{abstract}

Keywords: logistic cost, cost control, value chain analysis

\section{Introduction}

Since e-commerce enterprise springs up, its development momentum cannot be underestimated. However, rapid development inevitably brings about fierce competition. In order to stand out in the industry, e-commerce enterprises must strengthen their own competitiveness and enhance their core competence. Logistic cost, as one of the major constraints to the development of $\mathrm{B} 2 \mathrm{C}$ e-commerce, has been highly valued by the e-commerce enterprise. Especially for Pinduoduo, an enterprise whose core competitiveness is low price, how to control the logistic cost to increase the profit is worth studying. Additionally, what can't be ignored is that nowadays the realization of e-commerce enterprise value is not only in the production and service, but penetrates throughout the value chain. Therefore, under the constantly expanding market circumstance, forming the idea of value chain to increase the worth of customers and the companies is necessary.

There are two main purposes of the research. Primarily, the research attempts to analyze the current logistic mode of Pinduoduo and identify its logistic cost control measures from the aspects of internal value chain and external value chain, which could help better improve the efficiency of logistics costs management. In the meantime, in the views of the control measures and existing problems, the research tends to put forward some specific and practical suggestions to promote the sustainable development of the enterprise. This research may produce both theoretical and practical implications. Theoretically, most studies on logistics cost of e-commerce enterprise are only at macroscopic theoretical level, while this research aims to analyze the specific case from the perspective of value chain. This research combines the value chain theory with logistics cost control theory into practical application to provide a more complete analysis on the existing problems of the enterprise. Moreover, value chain analysis can effectively make a continuous review of current work practice to remove the non-value adding activities, improve the efficiency of the use of resources and increase the worth of the product or service to the enterprise and the customers. Practically, the research, which takes Pinduoduo as an example, analyzing its logistics cost control from the aspect of internal value chain and external value chain, is beneficial for the development of traditional e-commerce enterprises and stimulating more innovation ideas. Meanwhile, by 
proposing practical and feasible strategies towards Pinduoduo's logistics cost control problems, the research shall have certain reference value and guiding significance for other enterprises in the same industry.

\section{Literature Review}

The concept of "value chain" is defined by American professor Michael Porter of Harvard University (1985) in his book Competitive Advantage. Professor Porter (1985) thinks that the effective combination and perfection of enterprise-related value activities can promote the improvement of enterprise efficiency and competitive advantage. Johnson (1987) puts forward the cost idea of the value chain for the first time, and mentioned only by integrating and optimizing the value activities of enterprises in three aspects of strategy, resources and cooperation can enterprises exert the innovation power of the value chain and strive for greater market competitive advantage. Bovet et al. (1996) subsequently propose that the value network, taking the customer as the core, is a multi-link and multi-level value creation system composed of enterprise itself, suppliers and customers. Slywotzky (2003) points out that due to the increasing demand of customers, the impact of the Internet and the highly competitive market, enterprises should change their business design and transform the traditional supply chain into a value network. Value net connected the increasingly demanding demands of customers with flexible, efficient and low-cost manufacturing, and uses digital information to connect suppliers to increase efficiency. From the value chain to the value network, the value chain system is constantly improved. Estampe et al. (2013) propose that supply chain management creates value for companies, customers and stakeholders interacting throughout a supply chain. Brown (2014) believes that the significance of the value chain lies in dividing the activities of the enterprise into several parts to implement strategic management. Weill and Vitalei (2014) believe that through combining value chain analysis with the concept of strategic cost control, the cost can be effectively controlled. Collecting and analyzing the cost information on the value chain to optimize and perfect the value chain is also a key step. Based on the previous value chain cost control research, Min and Galle (2014) propose an important idea that reducing the inventory and transportation costs of enterprises from the value chain point of view can enhance its competitiveness.

Zhang (1997) puts forward the idea of value chain for the first time in China. He thinks that many of Michael Porter's viewpoints are very unique, and the method of analyzing the problem is also worth learning from. Xue et al. (2001) propose that the advantages of enterprises in competition come from some specific links in the value chain of enterprises. To maintain the strategic advantages of enterprises, the key is to control the strategic links in the value chain of enterprises. What's more, Zhao (2007) tries to use fuzzy linear programming method to study the optimization of enterprise cost value chain and considered the influence of time factor. However, up to now, most studies from the perspective of value chain were about theoretical analysis, less normative quantitative and empirical analysis. After that, Fan (2011) makes a detailed analysis of the cost structure of each functional link of logistics by using the value chain analysis method, and introduces activity-based costing method to analyze the cost driver, which highlights the advantages of value chain analysis, as well as the necessity and great potential of enterprise restructuring. To control the logistic cost, Zhang and Wang (2011) think that through introducing the concept of synergy into logistics activities and controlling logistics cost by means of synergy, the influence of "logistics cost inversion" will be reduced and this will become an effective way for enterprises to create value. While Wang and Hu (2012) point out that the main reasons for the high logistics cost are the low level of logistics management, the low concentration of logistics market and unreasonable charges in logistics transportation. After that, Zhang (2015) puts forward a time-driven activity-based costing method based on the analysis of the problems existing in logistics customer cost accounting and management. In addition, Zheng (2016) analyzes the internal value chain and the external value chain respectively and tried to form a relatively complete value chain system for the logistics cost control of e-commerce enterprises to create greater value.

The above researches show that logistics cost control plays an important role in enterprise cost management. Through the analysis of logistics cost control, management can make right logistics cost decision, reduce the total logistics cost and improve the economic benefits of enterprise and society. However, so far, the research on logistics cost control of e-commerce enterprises from the perspective of value chain is still mainly theoretical, and most of them focus on the single link control. This paper tries to make a more comprehensive analysis of logistics cost control from the perspective of internal value chain and external value chain. Meanwhile, in this paper, Pinduoduo is taken as an example to analyze. Through combining the theory with practice to analyze a specific case and giving feasible strategies, the research shall make much sense in practice. In addition, currently, there are very few studies adopting JIT and ABC methods to analyze the logistics cost control in the e-commerce enterprises, while JIT and $\mathrm{ABC}$ theories will be used in this research to give the enterprise more innovative ways to control the cost. 


\section{Theoretical Foundation}

\subsection{Logistic Cost Control Theory}

\subsubsection{Definition of Logistic Cost}

Logistic cost is the sum of all labor cost, material cost and financial resources consumed in the process of goods transportation, storage, packaging, loading and unloading, handling, circulation processing and others. The scope of the modern logistic cost is wider. It includes the total logistic costs from the beginning of the supply of the raw materials to the delivery of goods to the consumers.

\subsubsection{Composition of Logistic Cost}

Generally, logistic costs include transportation costs, inventory carrying costs, labour costs, customer service costs, rent for storage costs, administration costs, supplier costs and other costs. The share of each is as follows:

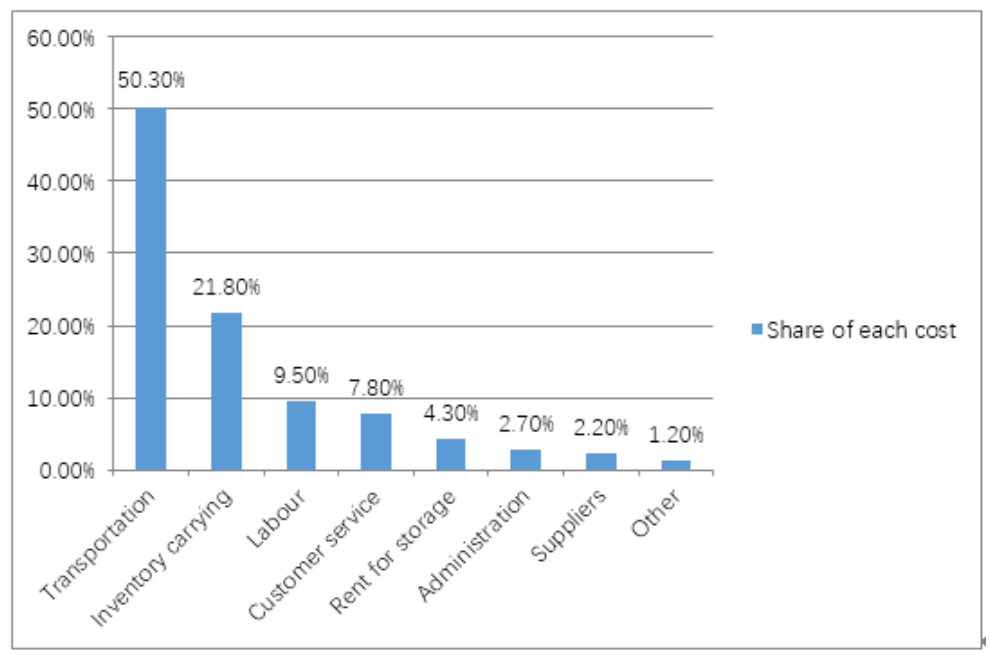

Figure 1. Share of each cost (Establish, Inc. / HWD \& Grubb \& Ellis Global Logistics)

\subsubsection{Logistic Iceberg Theory}

The logistic iceberg theory was proposed by Professor Seiichi of Japan Waseda University (Shuai, 2005). The theory holds that in enterprise, the vast majority of the logistic cost visible to people is mixed with other fees and is just only the tip of the iceberg above the water such as direct transportation and distribution charges, while many items of logistic costs in the interior of the enterprise hidden under the water are likely overlooked by people. Thus, when calculating the logistic cost, there must be a comprehensive consideration of both visible cost and invisible cost.

\subsubsection{Reverse Benefit (Alternating Profit and Loss) Phenomenon}

Generally speaking, among logistics functions, the cost reduction of one function will increase the cost of another function. Thus, it's hard to the enterprise to coordinate and optimize related logistic activities. For example, in the transportation process, the fastest transportation mode is air transportation, but the cost is high. On the contrary, if choosing waterway transportation, the time is longer but the transportation cost is lower. There is a trade-off between time utility and economic benefit. Another example, for logistic enterprise, it's a good way to lower the cost through reducing the inventory to lower the storage cost. However, if the inventory is reduced significantly, it may lead to a shortage or run out of stock, which will have an impact on the speed of responding to the customers. Therefore, because the costs are interrelated, the overall optimal logistic costs must be considered.

\subsection{Value Chain}

\subsubsection{Definition of Value Chain}

A value chain is a set of activities that a firm operating in a specific industry performs in order to deliver a valuable product (i.e. good and/or service) for the market. The concept comes through business management and was first described by Michael Porter in his 1985 best-seller, Competitive Advantage: Creating and Sustaining Superior Performance. 


\subsubsection{Composition of Value Chain}

\subsubsection{Internal Value Chain}

Internal value chain is the main activity of creating value for customers and related supporting activities. According to Porter (1985)'s value chain analysis, the value chain activities within the enterprise are divided into primary activities and secondary activities. The primary activities focus on the following functions of an enterprise:

1) Inbound logistics: Receiving, storage, and distribution of the inputs or raw materials.

2) Operations: All the activities that go into transforming the inputs into outputs that are then sold to consumers. Modifications to this step can help add value to the final product.

3) Outbound logistics: Getting your product to the final consumer - the delivery and distribution phase.

4) Marketing and sales: Efforts taken by the business to make the consumer aware of the product.

5) Service: Activities that maintain the value of the product or service after it is sold to the customer.

In addition to the five primary activities, there are also secondary activities that support the operations within certain primary activities. They include firm infrastructure, human resource management, technological development and procurement.

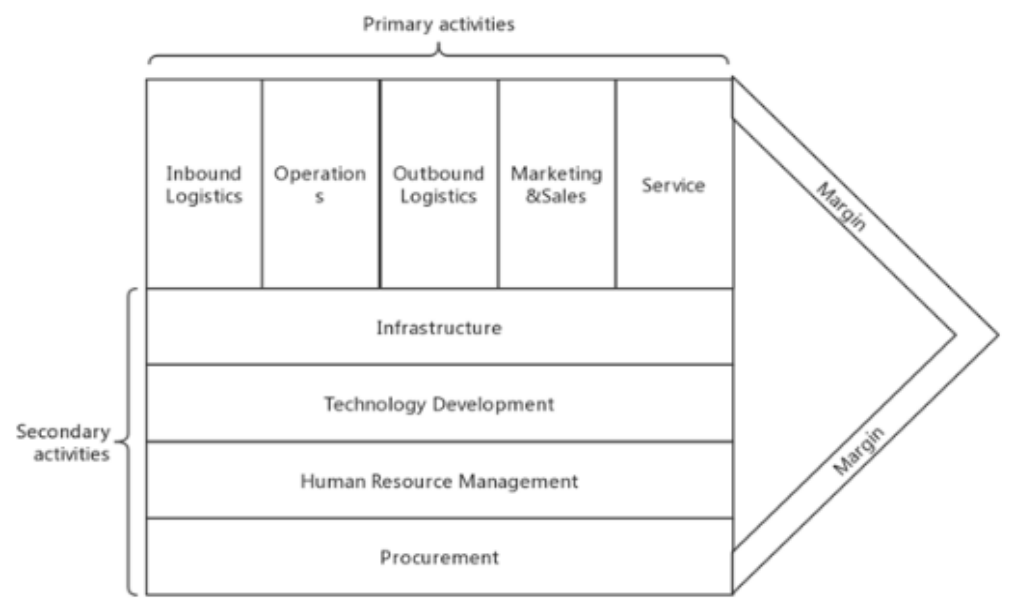

Figure 2. Corporate internal value chain activities (Michael, 1985)

\subsubsection{External Value Chain}

External value chain refers to value activities with external behavior subjects which are closely related to the enterprise. It mainly includes supplier value chain, customer value chain, competitor value chain and industry value chain as shown in the figure below. Internal value chain actually is a fundamental thought, which mainly focuses on internal business process to reach the aim of reduce the product cost by eliminating inefficiency and waste. While external value chain shows a high-level, strategic processing thought through introducing a comprehensive chain of operations beyond the enterprise itself into the business process.

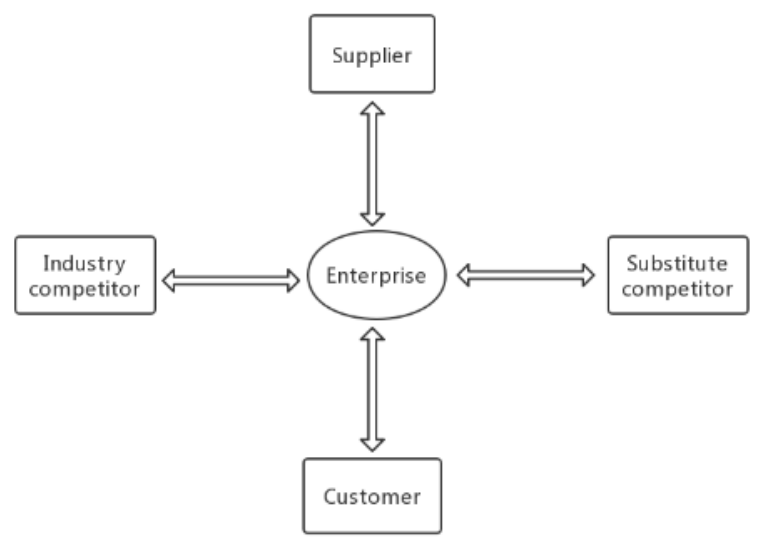

Figure 3.Corporate external value chain (Michael Porter, 1985) 


\subsection{Theories of Logistic Cost from the Perspective of Value Chain}

There are two meanings of value chain cost management. Firstly, the core enterprise should serve for the construction and optimization of the value chain, pay attention to not only its own interests, but also the interests of the value chain alliance enterprises. Secondly, the core enterprise needs to cooperate and communicate with the value chain alliance enterprises to establish a cooperation mechanism of information sharing, win-win benefit and risk sharing.

\subsubsection{Logistic Cost Control from the Perspective of Internal Value Chain}

For logistic cost of e-commerce enterprise, the cost control of internal value chain is actually applying activity-based costing and Just-In-Time to the value chain, which are good ways to control the procurement cost and storage cost.

The $\mathrm{ABC}$ method holds that the series of activities related to the product act as links in the chain, which makes the accounting cost analysis of the value chain possible. From the point of view of cost management, the value activity of an enterprise is cost behavior. Although managers of traditional enterprises can grasp the main component of enterprise cost, those value activities which account for a small proportion but are in a growing state and can eventually change the cost structure of enterprises are easy to be ignored. The application of value chain cost analysis method to cost management will change this situation. After the cost is apportioned in the value chain, it is used to compare the cost distribution of each value activity, so as to find out the breakthrough point that can improve the cost.

"Just-in Time" is a system whose objective is to produce and procure products or components as they are required by a customer or for use, rather than for inventory. A JIT system is a "pull" system as shown in the below figure which responds to demand, in which inventory acts as a buffer between the different elements of the system, such as purchasing, production and sales. A JIT production system, which is driven by demand for finished products whereby each component on a production line, is produced only when needed for the next stage. And it is required to maintain the stabilization, standardization and synchronization of the production process in the whole logistic supply. Through the JIT method, an enterprise may achieve the aim of producing the required items at the required quality and in the required quantities at the precise time they are required to lower the cost.

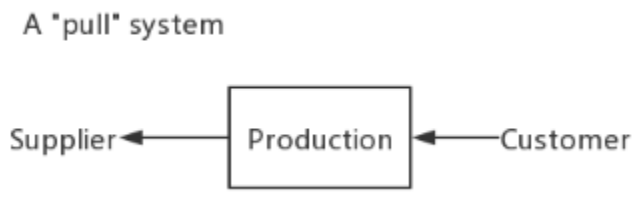

Figure 4. JIT "pull” system

\subsubsection{Logistic Cost Control from the Perspective of External Value Chain}

The key of cost control from external value chain is to form a relationship of trust with suppliers and customers, so that the collaborators can understand the cost and profit goal of the enterprise. To increase trust between partners is to establish responsible accounting management and reduce mistrust between companies by using accurate costing data to manage synchronized supply chains. Only when all partners really start to pay attention to their own costs and the costs of others can they work together to reduce total costs across the value chain and cut costs in the supply chain. Primarily, encourage the adoption of such processes by training suppliers and customers on responsibility accounting. A collaboration agreement is signed to ensure that all parties in the supply chain agree to use the information reflected by the responsibility accounting management to reduce the total cost added to the end user. The parties may jointly use the responsibility accounting management to determine which company is the cheapest to implement a certain link in the supply chain, thus controlling the overall cost. Finally, help distributors better understand their costs, including controlling order quantity, simplifying order difficulty, adjusting order frequency, etc.

\section{Case Introduction}

\subsection{Overview of Pinduoduo}

Pinduoduo Inc. is the largest e-commerce platform in China and biggest online market place for agriculture product sales. Founded in September 2015, the company has grown at an unexpected speed as consumers embraced its pioneering team purchase model and interactive e-commerce. Pinduoduo's motto of "Together, 
More Savings, More Fun" encapsulates its mission to help consumers realize more savings from their shopping and do so in a fun and engaging manner by aggregating user preferences and demand.

The trend of GMV of Pinduoduo indeed seems a good sign. GMV in the twelve month period ended March 31, 2020 rose to RMB1.2 trillion, surpassing the trillion-yuan mark in under five years, a rate of growth unmatched in the e-commerce industry.

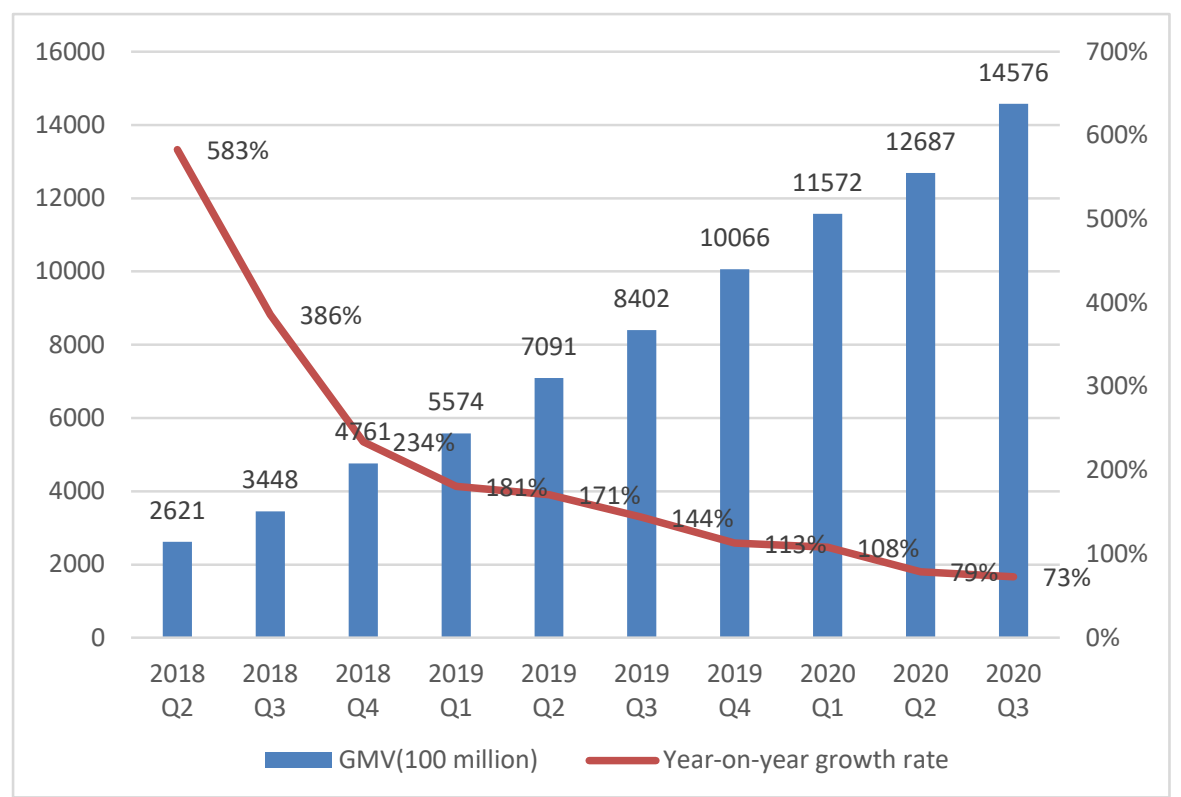

Figure 5. GMV trend of Pinduoduo (Pinduoduo Inc., 2018, 2019, 2020)

Apart from the increasing GMV, revenue also grows rapidly. In the third quarter of 2020, Pinduoduo's revenue was 14.2098 billion yuan, up 89 percent year on year. In the meanwhile, the revenue growth rate is higher than the growth rate of GMV, which indicates that Pinduoduo's liquidity rate is improving.

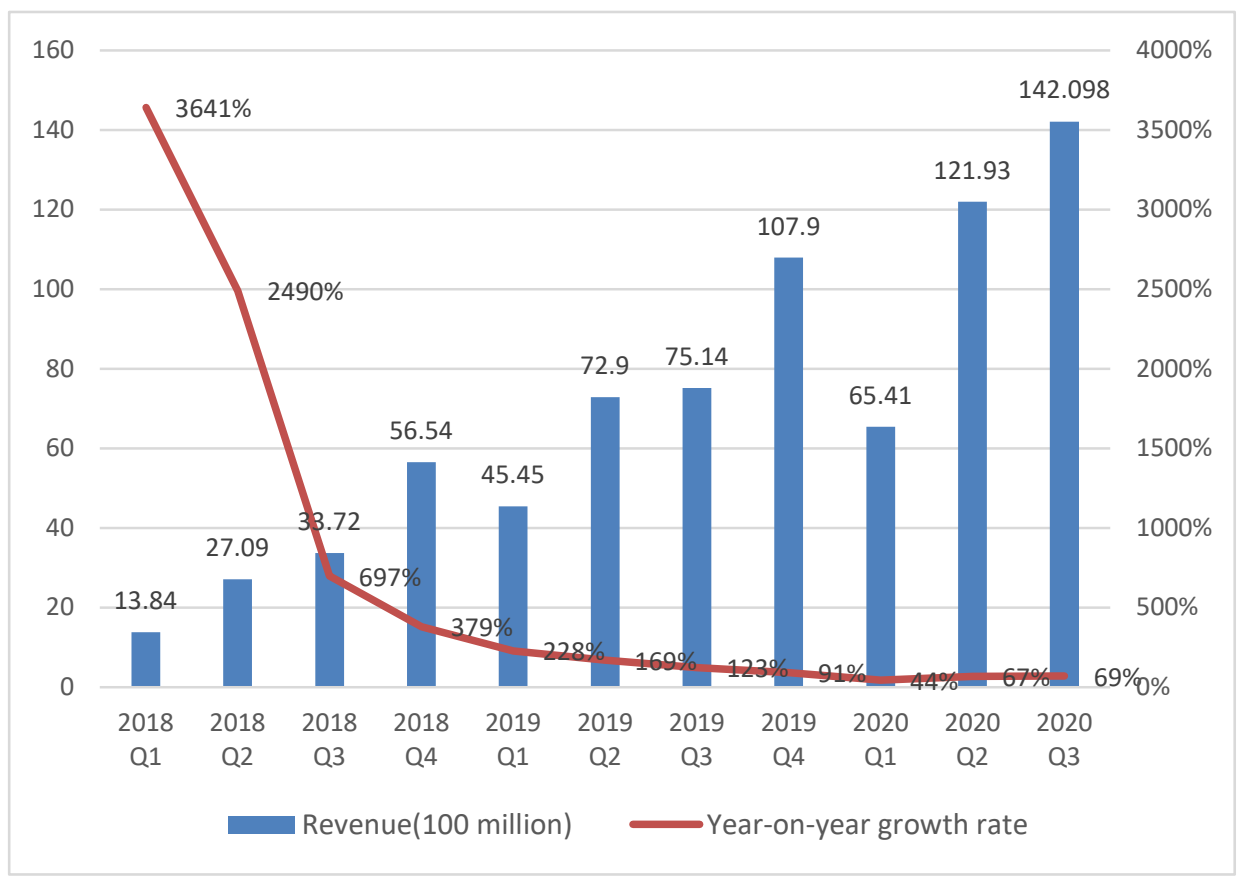

Figure 6. Revenue trend of Pinduoduo (Pinduoduo Inc., 2018, 2019, 2020) 


\subsection{Logistic Cost Status of Pinduoduo}

\subsubsection{Transportation Cost Status}

Currently, Pinduoduo adopts the third-party logistics model, which means it entrusts the logistic activities to professional service enterprises and keeps close contact with the information system, so as to achieve the whole-process logistic management and control. Its main basis for logistic service supervision is the dynamic score of the platform merchants. But in practice, the quality of the third-party can't be guaranteed.

\subsubsection{Procurement Cost Status}

Currently, most of the products of Pinduoduo are directly supplied by manufacturers, which can save a large part of costs resulting from the long production and marketing chain.

In addition, for the orders of multi-variety but small batch, Pinduoduo proposes "go together to buy" mode. Joint procurement is a kind of method which can reduce the purchasing cost of procurement. In most cases, in order to be able to increase the ability of risk prevention, several enterprises will join together to make a small order into a big order, through which they can enhance the capacity of collective bargaining and gain big purchase scale advantage. In this way, they will be able to get the most optimal price, best quality from the suppliers.

\subsubsection{Storage Cost Status}

Pinduoduo develops the strategy of unified factory and warehouse. Its warehouse is managed by the factory and brands owner. Since 2019, Pinduoduo is developing a "new logistics" technology platform, which will adopt a light-asset, open model and focus on providing solutions to merchants and users through technology. That means it doesn't construct warehouse, transportation and distribution itself, but maintains cooperation with upstream production and manufacturing enterprises and logistic enterprises. Under this situation, Pinduoduo establishes its logistic data network through technology means to lower storage cost.

\subsection{Value chain status of Pinduoduo}

From the perspective of value chain, actually Alibaba and JD have pioneered to make the main factor of value chain mature. Based on their mature system, Pinduoduo attempts to reconstruct the value chain between production, logistics and consumers and redistribute the benefits on the value chain to benefit manufacturers and customers.

The unique feature of Pinduoduo is that it adopts the "Pin Factory" mode. In December 2018, Pinduoduo launched the "New Brand Plan" to support brand upgrading of 1000 factories. This is a C2M (Customer to Manufacturer) mode which establish a very short link between customers and factories. "Pin Factory" C2M model is a subversion of the traditional supply-demand matching mode, from the past forecasting production to production according to demand orders. Through $\mathrm{C} 2 \mathrm{M}$ model, factories can design and produce based on a large volume of user preference data provided by Pinduoduo, shortening the new product development process by $50 \%$, such that new products can reach the market in a more timely fashion.

\section{Analysis of Logistic Cost Control Problem}

\subsection{Analysis from the Perspective of Internal Value Chain}

\subsubsection{Inadequate Supervision of Delivery Cost}

There are two reasons causing the problem. Firstly, as shown in the figure below, Pinduoduo's order mainly contracted in the third- and four-tier cities, thus although the revenue of Pinduoduo is high but the overall revenue per ticket is low. This doesn't mean cheap market make no sense. But when the delivery expense cannot cover its cost, there will be a thorny problem. According to Southern Metropolis Daily, in Shenzhen Huaqiang North, if there are 50-100 Pinduoduo orders every day, the express fee can be about 3-3.5 yuan per order. However, if the daily order volume reaches more than 1000, the express fee can compromise to 2.6-2.8 yuan per order. But many express companies do not accept this order, because 3.5 yuan per order is already the express delivery cost. Besides, cheap orders often are not attached importance, which may lead to halfway missing. 


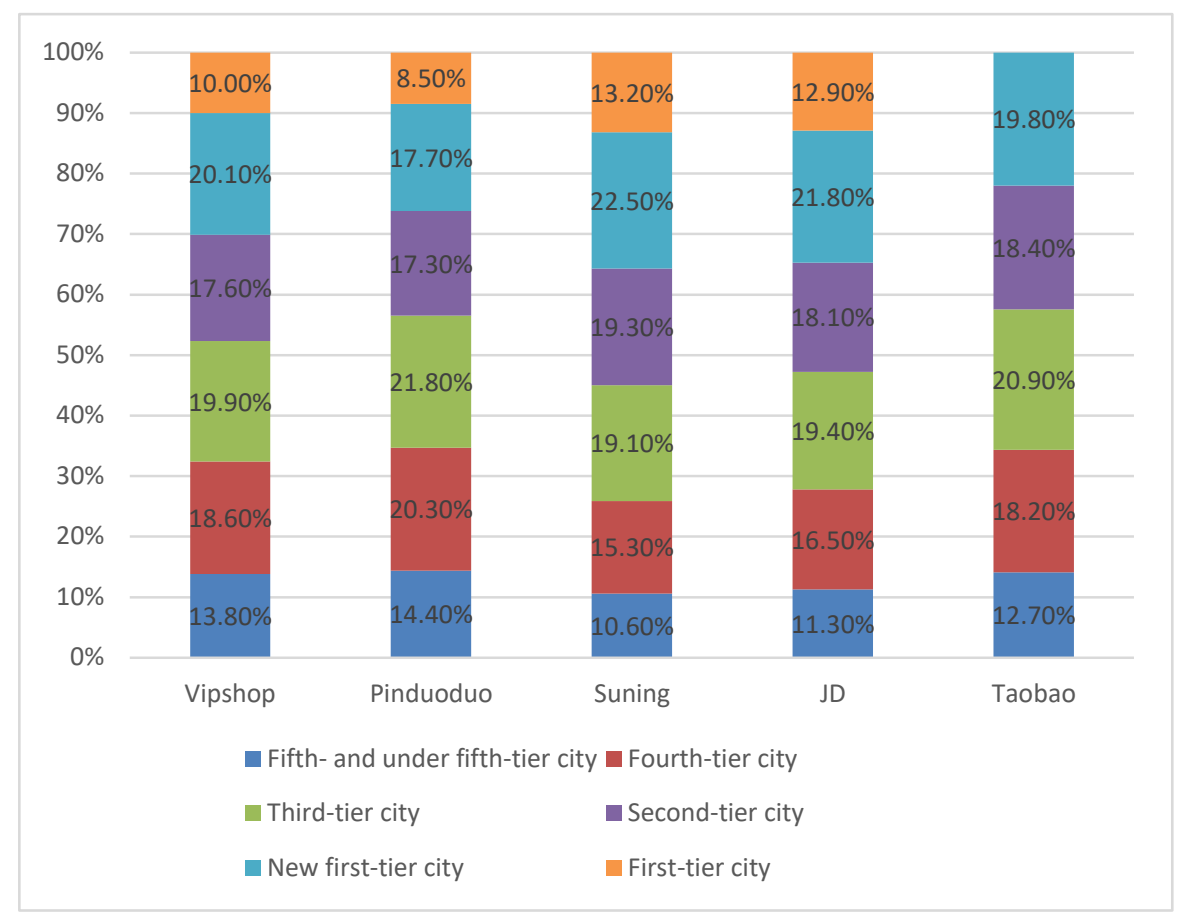

Figure 7. Distribution of active users by city on November 11, 2020 (Aurora Mobile, NASDAQ:JG, 2020)

Secondly, since Pinduoduo does not have its own logistics system, it is all handed over to merchants for unified delivery. In order to reduce the logistics cost, merchants will choose the logistics with low service, low efficiency and low standard for distribution. There will be slow delivery, slow logistics distribution. The demand is large, but the distribution capacity cannot keep up. This also leads to the inconsistent quality of logistics. Pinduoduo needs to take stricter measures on the supervision of logistic.

\subsubsection{Low Freight Rate, High Logistic Cost}

Transportation cost accounts for the largest proportion among logistic costs. The ability of transportation management directly reflects the level of logistics. However, currently, low price competition in the freight market makes quality logistic service scarce, exacerbating the rise of logistic cost. There are two reasons leading to it.

Firstly, the truck can't match with the cargo. In transportation process, goods and vehicles cannot achieve intelligent matching, resulting in relatively excess capacity, low efficiency, low degree of organization, which is the core crux of restricting the decline of logistic costs. Pinduoduo now mainly adopts the third-party logistics model and Pinduoduo's products are directly supplied by the manufacturers, which means the merchants choose the carriers, so the quality and efficiency cannot be controlled. After the order is issued, the carrier needs to find suitable vehicles. Freight rate can go up to $50 \%$ to find the suitable cars. Sometimes enterprises may encounter increasing freight price, which greatly increases financial costs and logistic costs. So the precise matching of goods and vehicles is still a problem plaguing Pinduoduo's efficient logistics. Secondly, Pinduoduo's information trading mode lags behind. Because has not yet build its intelligent logistics platform, it's also very unfavorable on transportation.

\subsubsection{High Reverse Logistic Cost}

Reverse logistic cost refers to the cost when the customer entrusts the third party logistics to return the goods to the merchant. Pinduoduo's after-sales service has been a big problem. As shown in the figure below, the main reasons for customer' complaints are product quality and refund problems. So the reverse logistic cost is born by Pinduoduo. The amount involved in the complaints is high, which is a big loss for Pinduoduo. 


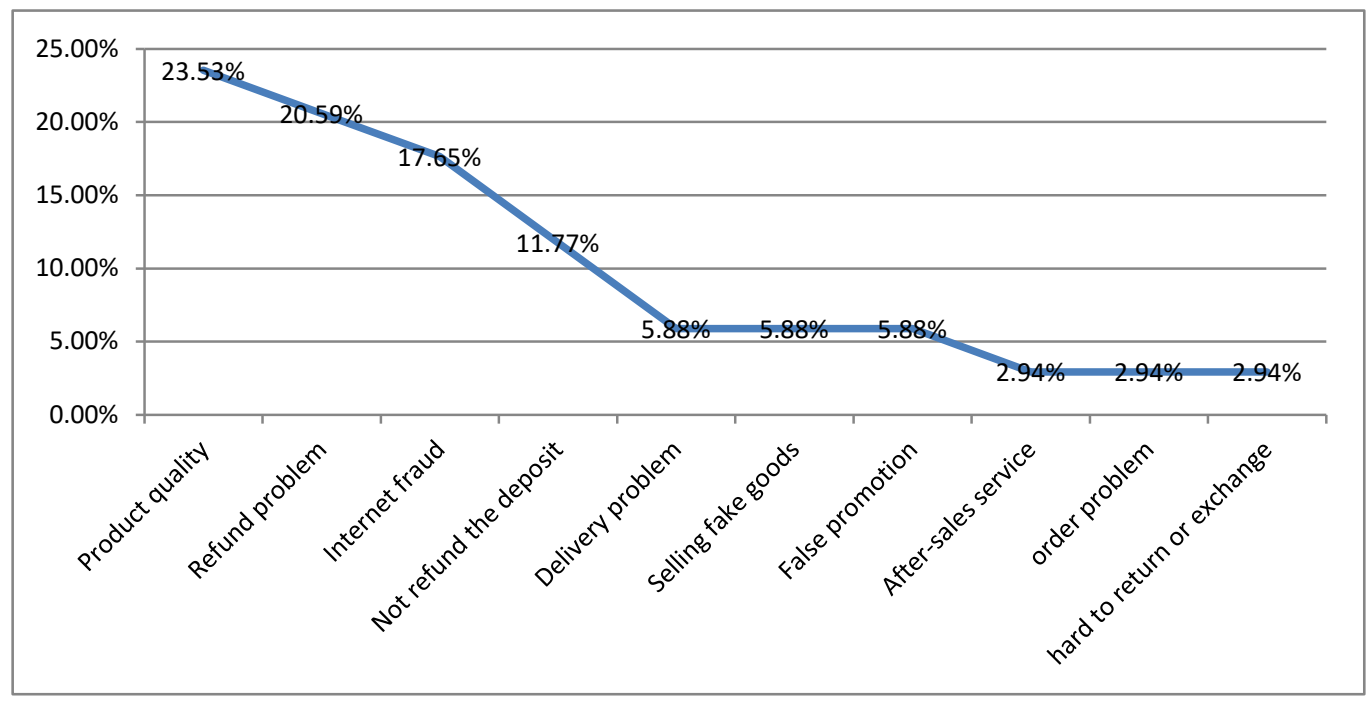

Figure 8. Percentage of complaints (China e-Business Research Center, 2020)

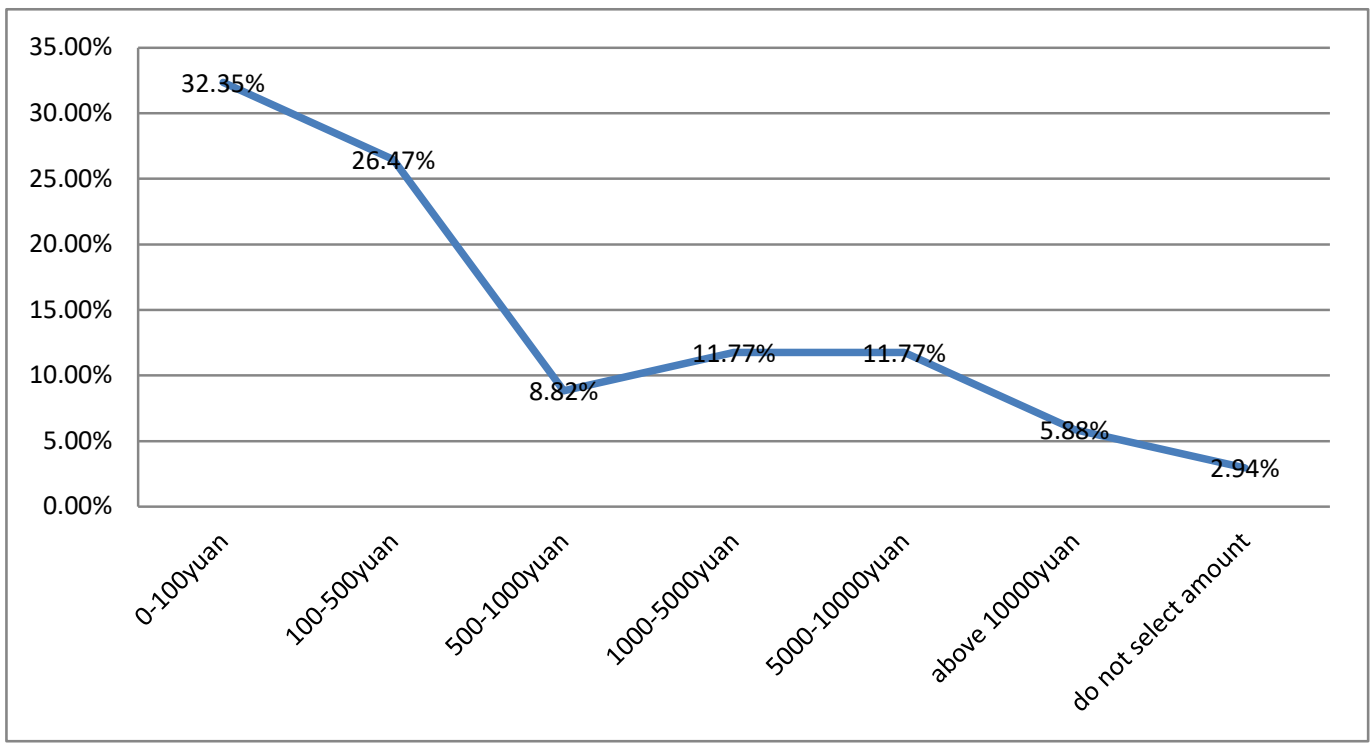

Figure 9. The proportion of the amount involved in the complaints (China e-Business Research Center, 2020)

There are two main reasons leading to this problem. Firstly, quality control is insufficient. Pinduoduo's marketing strategy is based on product hot style, often leading to a short-term spike in the single volume. It's likely to follow the trend to buy unpractical things. The possibility is high because the price of the products is low and the quality cannot be highly guaranteed. Therefore, there will be a very high rate of returns. Many buyers received fakes and faced difficulties in returning goods and defending their rights. Both businesses and platforms will find reasons to shift responsibility, or even to the buyers. High rate of returns also reflects the low satisfaction rate. This will further increase the cost of service. Secondly, the reverse logistic system is imperfect. In fact, Pinduoduo is not directly involved in the return process. Instead, the merchant is responsible for selecting the logistic company. Therefore, Pinduoduo can't get the information on time and can't effectively integrate logistic information.

\subsection{Analysis from the Perspective of External Value Chain}

\subsubsection{Lack of Users Loyalty}

The lack of logistics service experience brought by Pinduoduo to consumers is the fatal weakness of Pinduoduo's further development. Under consumption upgrading era, consumers will increasingly begin to pursue high quality, efficient logistics and e-commerce enterprise with good experience. When customers are not attracted by the low price in Pinduoduo, it will lose a lot of users. Besides, Pinduoduo doesn't form a good relationship 
network in customer retention. Compared to Taobao, there is no buyer credit system in Pinduoduo. So sellers will be more likely to lose in the order dispute and be deducted margin, which will lead to less sellers registering in Pinduoduo. Also this may increase the complaints of both customers and suppliers.

\subsubsection{High Competitiveness of Competitors}

Logistic service and timeliness is a yardstick by which customers measure e-commerce. Under this market, big data is essential to competition. From the perspective of timeliness and complaint rate, e-commerce companies with logistics or holding logistics can have a better right to speak. This is the reason why JD established "boundless logistic" before. According to the State Post Bureau, in the first half of 2019, the volume of express delivery service enterprises across the country totaled 27.76 billion pieces, up 25.7 percent year on year, while Pinduoduo's parcel volume exceeded $25 \%$ of the country's total express volume in the first half of this year. As Pinduoduo grows, there will be more pressure and exclusion from the enterprise in the same industry. Ali has collected four express companies, including YTO, STO, ZTO and Best Express, except YUNDA. So Ali has a great share and power. If Pinduoduo wants to compete, it seems the only way for Pinduoduo is to acquire existing express companies or own self-established logistics. But it's impossible after considering the time cost. Thus, this is still a challenge for Pinduoduo.

\subsubsection{Imperfect Sinking Market Value Chain}

Pinduoduo's sales of agricultural and sideline products have been growing at a rapid rate in recent years. In 2020, the transaction volume of Pinduoduo's agriculture products is 270 billion yuan, double the scale of the same period last year, accounting for $16.2 \%$ of the annual transaction volume, which is higher than the industry's average ratio of about $3 \%$.

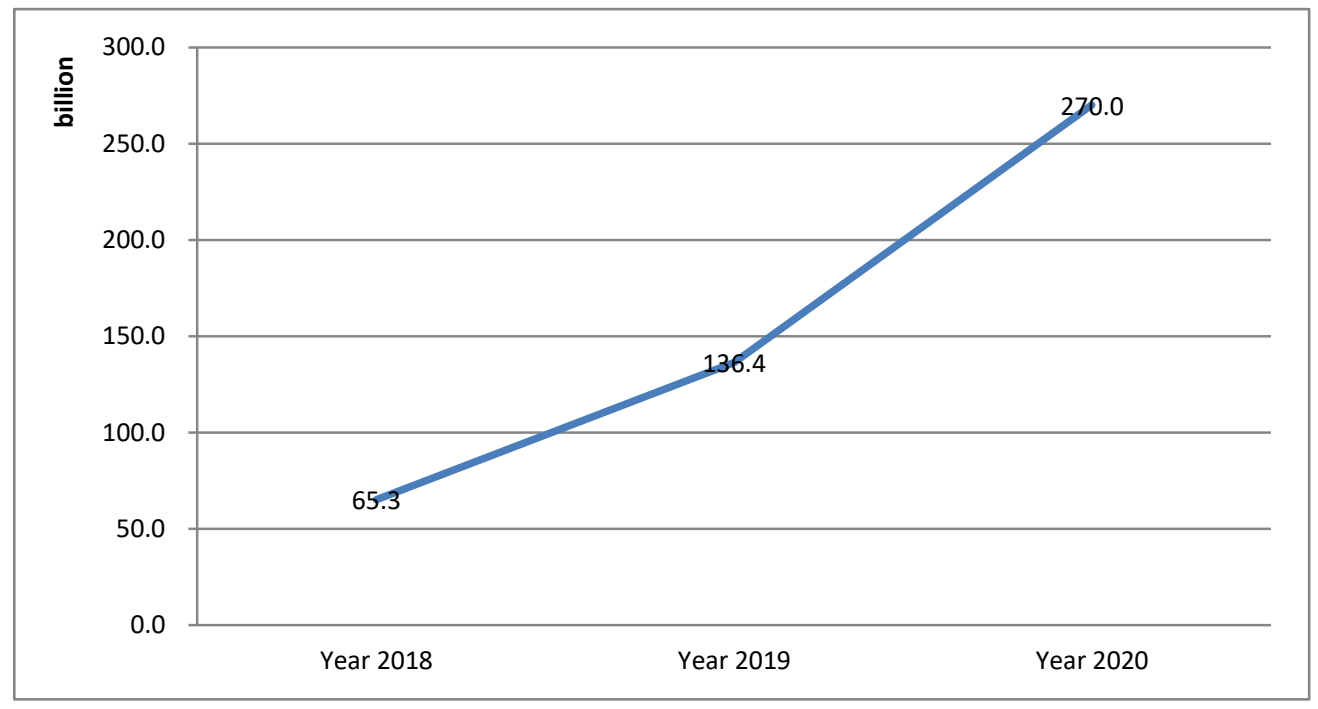

Figure 10. Turnover of agricultural and sideline products in Pinduoduo from 2018 to 2020 (Pinduoduo Inc., 2018, 2019, 2020)

Pinduoduo was the first e-commerce platform to enter the sinking market and rise by surrounding cities from rural areas. But actually customer demand in a sinking market is even more demanding. For example, in the first and second tier market, high price can naturally guarantee the good quality of products, while in the sinking market, they prefer low price but still basic or good quality. In addition, urban logistic networks are well developed, but warehousing and distribution remains a problem for many towns and villages. The key to solve the problem is to build a perfect logistic value chain and supply chain. This is a shortage for Pinduoduo because its main logistics mode is third-party logistics. In terms of this issue, Pinduoduo launched a "Duoduo orchard" plan, which is a "new agricultural business" mechanism. Under this mode, Pinduoduo provides fund, technology to support, and cultivates local youth as leaders of the new plan. But this model still faces challenges. The first problem is a shortage of leading farmers. Moreover, it's unknown whether it can promote the industry drive effect.

Apart from that, in the circulation link, lack of cold-chain is a common problem in agricultural products transportation in China because of the characteristics of fresh goods of difficult to store and transport, easy to 
wear, high requirements for delivery time and low product standardization. For example, for some fresh fruits and vegetables, there is no corresponding cold chain distribution, resulting in the deterioration and destruction of fresh vegetables in the hands of buyers. Therefore, for agricultural goods industry chain transformation, branding and scale, there is still a long way to go for Pinduoduo.

\section{Suggestions}

\subsection{Suggestions from the Perspective of Internal Value Chain}

\subsubsection{Using JIT and ABC Methods to Lower the Procurement and Storage Cost}

Currently, Pinduoduo develops the strategy of unified factory and warehouse. Although this is a good way to lower the procurement and storage cost, there is still a big problem for fresh goods to reduce losses. In response to this problem, Pinduoduo can adopt JIT analysis. A product is not "made" until they are required by the next production stage. In this way, the enterprise can achieve virtually no holding inventory. But it's worth noting that as Pinduoduo must form strong relationship with suppliers. And suppliers should take responsibility for the quality of their goods. On the other hand, for the storage cost, Pinduoduo can adopt the ABC analysis. First, management and staff must determine which activities are critical to success and everyone should co-operate in defining the cost pool, cost drivers and key performance indicators. Then, for products with few variety but high occupation of capital, they should be regarded as the key control objects and must be controlled strictly, while for products that are not so important, generally Pinduoduo can only need to take some simple control measures.

\subsubsection{Strengthening the Supervision of Delivery Cost}

Firstly, always keep close communication with merchants, in case that they choose a low quality of logistic ways for reducing their own benefits. Generally, through repetitive game credit mechanism can be created. Pinduoduo can set up a strict scoring system for merchants for the delivery time and quality.

Secondly, in order to resolve the contradiction of low freight rate and high logistic cost resulting from mismatch of vehicles and goods, the logistic data should be digitalized and information-based. With the help of intelligent logistics, the unit freight and transportation distance from the supplier to customer can be calculated and then the optimal transportation plan can be designed, so as to improve the return empty vehicles utilization rate, reduce the time and cost vehicles spending on the physical stowing station. In addition, increase cargo load. That means to make full use of vehicle load tonnage and loading capacity. For bulky items that are dismountable, break them down to save space and avoid damage.

\subsubsection{Improving the Efficiency of After-sale Service to Lower Reverse Logistic Cost}

As the after-sale service greatly affects customer satisfaction and retention, it's essential to improve the efficiency of after-sale service to decrease the rate of return and complaints. Firstly, strengthen the supervision of merchants and the control of product quality. For products, enhance the inspection of product quality. There shouldn't hold a post without qualification to reduce the cost. And pay attention to the package of products in case of damage or loss. Moreover, give a highly focus on the feedback of customers to improve the performance. For merchants, establish a fair and transparent business scoring mechanism.

Secondly, improve reverse logistic system. It is advisable for Pinduoduo to establish a closer link with logistics companies. In this way, it can get the information of customers from the logistic companies, and when customers have any feedback and requirement, Pinduoduo can have a quick response.

\subsection{Suggestions from the Perspective of External Value Chain}

\subsubsection{Enhancing relationship with Suppliers}

Establishing long-term strategic partnership with upstream suppliers plays an indispensable role in the long-term development of e-commerce enterprises. Because Pinduoduo adopts the strategy of "Pin" mode, form a good relationship can benefit both suppliers and the enterprise. It's advisable that to sign a contract before cooperation and each party should strictly obey the rules. If any side breach, it must bear the liability for the breach of contract and pays high litigation cost. This is an essential rule especially for short-term and a single transaction. Apart from that, Pinduoduo can provide information of customers to help the suppliers to better manage the production and storage.

\subsubsection{Establishing Strong Relationship with Customers}

Pinduoduo should improve the professionalism of the staff. Give them training if necessary to improve the experience of customers. For serviceman, they should be polite and try to satisfy customers' needs. When customers have placed an order, they should let them make a check again. Products which meet the rules of 
return or exchange shall be returned or replaced. Additionally, collect and analyze the feedback from customers to understand their needs and get an insight to their tastes. And every part of the value chain should make adjustment to customer feedback. For example, the R\&D Department can make adjustment based on the customer behaviors.

\subsubsection{Forming an Infallible Information System}

Under the information system, every part of the value chain is able to achieve information sharing. With the help of big data, storage, transportation and distribution process can monitored and optimize through the technology. So Pinduoduo should make a combination of logistics and information stream to optimize the value chain, through which it can achieve effective resource usage and get more competitive advantages. For cold-chain logistics, Pinduoduo should consider the seasonal problems to reduce losses. Moreover, collect the information of customer preferences and share the data with the farmers and merchants. Try to stock up on demand and deliver to customers the same day or the next day as far as possible.

\section{Conclusion}

This paper makes an analysis of the logistic cost of Pinduoduo from the perspective of the value chain and attempts to give suggestions based on the existing problems of Pinduoduo's logistic cost, which shall be of great significance to other e-commerce enterprises.

Based on our research and analysis, we find that for internal value chain of Pinduoduo, it faces problems of inadequate supervision of delivery cost, unreasonable freight rate, and high reverse logistic cost. For external value chain, Pinduoduo faces problems of low loyalty from users, high competitiveness from competitors and imperfect sinking market value chain. Aiming at these problems, this paper puts forward the following suggestions. For internal value chain, Pinduoduo should adopt JIT and ABC method to help reduce the procurement and storage costs, strengthen the supervision of delivery cost by keeping close communication with merchants and make good use of intelligent logistics, and improve the efficiency of after-sale service to reduce the reverse logistic cost. For external chain, Pinduoduo should form good relationship with suppliers and customers. In the meantime, establishing an infallible information system is essential for Pinduoduo.

Although this paper has analyzed the logistic cost from the perspective of value chain, there are still some insufficiencies. First, the data about Pinduoduo is not enough and comprehensive. Secondly, as the value chain of Pinduoduo is still establishing, there may be a big change in the future. Lastly, this paper doesn't make much comparison of Pinduoduo in different periods and with other enterprises, so there may be a lack of an insight of the whole industry. In the end, hope this paper shall be a help to the whole e-commerce industry.

\section{References}

Adrian, J. S. (2003). The Profit Zone. Random House US.

Aurora Mobile, NASDAQ: JG. (2020). Research Report on "Double 11" Sales of the E-commerce Industry. Retrieved from https://m.jiguang.cn/reports/522

Brown, L. (2014). Competitive Marketing Strategy. Nelson, Melbourne.

China E-Business Research Center. (2020). Credit Rating Database of E-commerce Enterprises. Retrieved from http://www.100ec.cn/Index/complaintData.html

David, B., Kirk, K., \& Joseph, M. (1996). Value Net. New York: Wiley \& Sons.

Dominique, E., Samir, L., Jean-Luc, P., \& Brahim-Djelloul, S. (2013). A Framework for Analyzing Supply Chain Performance Evaluation Models. International Journal of Production Economics, (4), 247-258. https://doi.org/10.1016/j.ijpe.2010.11.024

Dongping, Z. (2007). Quantitative Analysis Approach for Business Cost Control Based on the Optimization of Value Chain. Journal of Modern Information, (12), 192-194.

Hui, Z., \& Yan, H. (2020). Analysis of the Reverse Logistics of Pinduoduo and Its Development Strategy. Modern Economic Information, (14), 140-141.

Johnson, K. (1987). Management Accounting. Harvard Business School Press.

Liheng, Z. (2015). Accounting and Management of Logistics Client Cost Using Time-driven ABC. Logistics Technology, 34(13), 153-156, 176. https://doi.org/10.3969/j.issn.1005-152X.2015.07.049

Mengxin, F. (2011). Analytical Method for Logistics Cost Based on Value Chain. Jing Ji Wu Liu, (5), 37-40.

Michael, P. (2005). Competitive Advantage. Beijing: Huaxia Publishing House. 
Michel, E. P. (1985). Competitive Advantage. New York: Free Press.

Min, H., \& Galle, W. P. (2014). Electronic Commerce Usage in Business-to-business Purchasing. International Journal of Operations \& Production Management, $19(9), \quad 909-921$. https://doi.org/10.1108/01443579910280232

Mo, Z., \& Chen, W. (2011). The Coordinative Strategy of Logistics Cost Control. Economic Forum, 485(1), 141-144.

Pinduoduo Inc. (2018). Annual Report. Retrieved from https://investor.pinduoduo.com/financial-information/annual-reports

Pinduoduo Inc. (2019). Annual Report. Retrieved from https://investor.pinduoduo.com/financial-information/annual-reports.

Pinduoduo Inc. (2020). Annual Report. Retrieved from https://investor.pinduoduo.com/financial-information/annual-reports

Weill, P., \& Vitale, M. (2014). Place to Space: Migrating to E-Business Models. Harvard Business School Press.

Xubo, Z. (1997). Corporate Behavior and Competitive Advantage - Comments on Michael Porter's Value Chain Theory. International Economics and Trade Research, (03), 34-37. https://doi.org/10.13687/j.cnki.gjjmts.1997.03.009

Yunjian, X., Ailan, L., \& Qiyao, Y. (2001). Value Chain and International Marketing Strategy. China Business \& Market, (01), 48-51. https://doi.org/10.14089/j.cnki.cn11-3664/f.2001.01.015

Yuqin, W., \& Yibo, H. (2012). Study on Reducing Logistics Cost for B2C E-commerce Enterprises. Logistics Technology, (63), 204-206. https://doi.org/10.3969/j.issn.1005-152X.2012.08.070

Zhenghui, Z. (2016). Value Chain Cost Management of Business Enterprises. Money China, (12), 100-110. https://doi.org/10.16266/j.cnki.cn11-4098/f.2016.08.095

\section{Copyrights}

Copyright for this article is retained by the author(s), with first publication rights granted to the journal.

This is an open-access article distributed under the terms and conditions of the Creative Commons Attribution license (http://creativecommons.org/licenses/by/4.0/). 